\title{
Bacteriological profile and Antimicrobial Susceptibility pattern of isolates from Urinary Tract Infections in Eastern Uttar Pradesh, India
}

\author{
Lekha Tuli ${ }^{1 *}$, Sujeet Rai ${ }^{2}$, Dilshad Arif ${ }^{1}$, Deepak K. Singh ${ }^{3}$ \\ ${ }^{1}$ Department of Microbiology, Mahamaya Rajkiya Allopathic Medical College, Ambedkar \\ Nagar, Uttar Pradesh, Pin code- 224227, India \\ ${ }^{2}$ Department of Anaesthesia, Mahamaya Rajkiya Allopathic Medical College, Ambedkar Nagar, \\ Uttar Pradesh, India \\ ${ }^{3}$ Department of Surgical Oncology, Tata Memorial Hospital, Parel, Mumbai, Maharashtra, India \\ *Corresponding author
}

Keywords

UTI,

Kidney stones, Uropathogens, Antibiotic resistance, Disk diffusion method.

\section{Article Info}

Accepted:

18 February 2016 Available Online: 10, March 2016
This study was conducted in Ambedkar Nagar district from August 2012 to January 2016 to see the prevalence of various bacteria causing Urinary Tract Infections in patients with burning micturition, kidney or ureteric stones, pregnant women and catheterised patients. The antibiotic susceptibility pattern of these isolates was studied.The maximum patient group presented with burning micturition (63\%) followed by kidney stones $(16.5 \%)$ and pregnant women $(10.4 \%)$. Of a total number of 1078 urine samples Escherichia coli showed maximum growth (49.5\%) followed by Klebsiella pneumoniae (24.7\%), Pseudomonas aeruginosa (9.5\%), Proteus mirabilis (5.1\%), Citrobacter freundii (2.5\%), Enterobacter (1.9\%), Staphylococcus aureus (2.1\%), Staphylococcus epidermidis (1.3\%) and Enterococcus spp.(1.02\%).Most of the isolates showed susceptibility to Amikacin followed by Nitrofurantoin. The isolates were found resistant to Amoxiclav and Co-trimoxazole. The increasing trend of resistant strains depicts the misuse and indiscriminate use of antibiotics and warrants attention. This is the first study from this area where patients with high incidence of kidney stones have been reported.

\section{Introduction}

Urinary tract infection (UTI) is one of the most commonly occurring community acquired infections in developing countries owing to lack of sanitation and unhygienic toilet habits. Normally urine in the urinary bladder is sterile (Humayun et al., 2012). The detection of pathogenic microorganisms in the kidney, bladder, urethra or urine with or without symptoms is called UTI. Faecal flora may reach the bladder via the urethra due to retrograde ascent (Al-Jebouri et al., 2013). It is more common in females due to presence of shorter urethra. The other predisposing factors being use of contraceptive methods (diaphragms, spermicidal agents), menopause, urinary 
tract abnormalities, blockage in the tract due to kidney stones or benign prostatic hyperplasia (BPH), suppressed immune system, catheterisation or any surgical intervention of the urinary tract. The infection may be symptomatic or asymptomatic and mostly, the condition may not be life threatening but if kidneys are involved the damage may not be repaired.A complicated UTI involves both upper and lower tracts. Urinary Tract Infection may occur in all age groups. The most commonly occurring bacterial uropathogens being Escherechia coli, Klebsiella spp., Proteus spp., Citrobacter spp., Pseudomonas spp., Staphylococcus spp. and Enterococcus spp. Although UTI may not be fatal but the growing incidence of resistance to the commonly used antibiotics interferes with effective treatment and poses a serious threat for the future therapeutic regimen.

This study was aimed to determine the bacteriological profile and antibiotic susceptibility pattern from cases of urinary tract infections in Eastern Uttar Pradesh. This is the first study from this area which caters the patients from the districts of Ambedkar nagar, Basti, Sant Kabir nagar, Faizabad, Jaunpur, Azamgarhetc. and reports a high incidence of kidney stones in the residing population.

\section{Materials and Methods}

\section{Place and period of study}

The study was conducted in the Department of Microbiology, MRA Medical College, Ambedkar Nagar, UP, India from August 2012 to January 2016.

\section{Study Cases \\ Inclusion criteria}

The urine samples were collected from cases presenting with complains of burning micturition, catheterisation, kidney or ureteric stones (confirmed by Ultrasound) and recurrent UTI; and frompregnant women. Samples were also collected from asymptomatic cases (pregnant women in the first trimester and in preoperative urologic surgery cases).

\section{Exclusion criteria}

Patients presenting with any other complain and those who were already on an antibiotic treatment were not included in the study.

\section{Sample collection and processing}

A total of 3261 urine samples which came for routine culture and sensitivity diagnosis were taken from patients of all age groups and their age, sex, address and clinical diagnosis were recorded. Early morning, midstream clean catch urine samples were collected in sterile disposable wide mouthed containers. In case of elderly patients and infants where sample collection was difficult suprapubic aspirates were obtained. In catheterised patients, the catheter tube was cleaned and clamped and samples were collected aseptically using disposable syringes. A consent was taken from the patients before performing the above procedures.

\section{Direct Microscopy}

Urine samples were first subjected to wet mount examination to check for the presence of microorganisms, pus cells, epithelial cells, RBC's and crystals.

\section{Bacteriological Examination}

The urine samples were put for culture with the help of sterile standard calibrated inoculation loop on MacConkey Agar, 
nutrient agar and blood agar plates by semi quantitative method and incubated aerobically at $37^{\circ} \mathrm{C}$ overnight. The samples showing colony counts of $\geq 10^{5}$ colony forming units $(\mathrm{CFU}) / \mathrm{ml}$ were considered positive. These isolates were identified on the basis of colony morphology, microscopy and biochemical reactions (Indole, Triple Sugar Iron, Citrate, Urease, Oxidase, Methyl Red, Voges Proskauer, Catalase, Coagulase tests).

\section{Antibiotic Susceptibility Testing}

As per the CLSI (Clinical Laboratory Standards Institute) guidelines, the isolated bacteria were put to antibiotic susceptibility testing on Mueller Hinton agar by KirbyBauer disk diffusion method (Bauer et al., 1966).The isolates were tested for Amoxiclav, Amikacin, Ceftazidime, Ciprofloxacin, Cotrimoxazole, Gentamicin, Nitrofurantoin and Norfloxacin antibiotics. A lawn of the test organism was evenly spread on the agar plate with the help of a sterile swab and the antibiotics were put on it and incubated at $37^{\circ} \mathrm{C}$ for 24 hours. In case of formation of zone of inhibition, the diameter was measured in millimetres with the help of scale and were grouped as sensitive, intermediate or resistant as per the reference diameter range provided by the manufacturer (Hi Media, Mumbai, India).

\section{Results and Discussion}

Of the total number of 3261 urine samples collected, growth was observed in 1078 samples. The remaining were either sterile or did not show any significant growth. Of the samples positive for bacterial growth the maximum cases $(47.5 \%)$ were that of females in the age group between 18-60 years of age. Similar results were obtained by Humayun et al. (2012). This is because in females the urethra has close proximity and the colonic bacteria have an easy access to it. Females are more prone to UTI than males as they lack bacteriostatic property of prostatic secretions (Al-Jebouri, 1989).In a study by Kebira et al. (2009) too, the authors found a higher incidence of UTI in the females of the same age group.UTI may occur in women of this reproductive age group owing to sexual activities and multiple sex partners. The use of intra uterine devices and other barrier methods may lead to UTI in females. Of these females with UTI, 10.4\% were pregnant. A gravid uterus during pregnancy may exertpressure on the ureters leading to urine retention and the hormonal changes lead to dilatation of renal pelvis and ureter, decreased bladder tone and less peristalsis leading to increased risk of UTI.

The maximum patients $(63 \%)$ presented with the complaint of burning micturition, fever, and abdominal discomfort (Fig. 1) which was followed, by occurrence of UTI in pregnant females (10.4\%). Around 16.5\% occurrence was found in patients with ureteric or kidney stones. Al-Jebouri (2013) in a study from Iraq reported $4.3 \%$ of their subjects having UTI due to stones. In a study conducted by Pawan et al. (2013), they found a high incidence of renal stones in northern India. Another study from Bundelkhand area of Uttar Pradesh also reported prevalence of kidney and ureteric stones (Bhargava et al., 2012).These areas may fall into the stone belt region of the country owing to high incidence of patients with kidney stones. Catheterised patients (5\%) and asymptomatic cases (5\%) comprised the remaining of the study group. Rajagopalan (2000) also found around 40\% of catheterised and hospitalised patients suffering with UTI due to Escherichia coli. Asymptomatic bacteriuria may be due to many reasons. Cases of asymptomatic bacteriuria can be found in patients with diabetes and pregnant women (Schneeberger et al., 2014). HIV patients may present with 
asymptomatic bacteriuria (Omoregie et al., 2009). A study found association of obesity and Iron deficiency anemia with asymptomatic bacteriuria in hospitalised patients (Cuttitta et al., 2014). Our study group mainly comprised of people from lower economic status. Other studies have also shown correlation of lower economic status with UTI (Turck et al., 1962).

Figure.1 Prevalence of UTI in the patients based on clinical symptoms

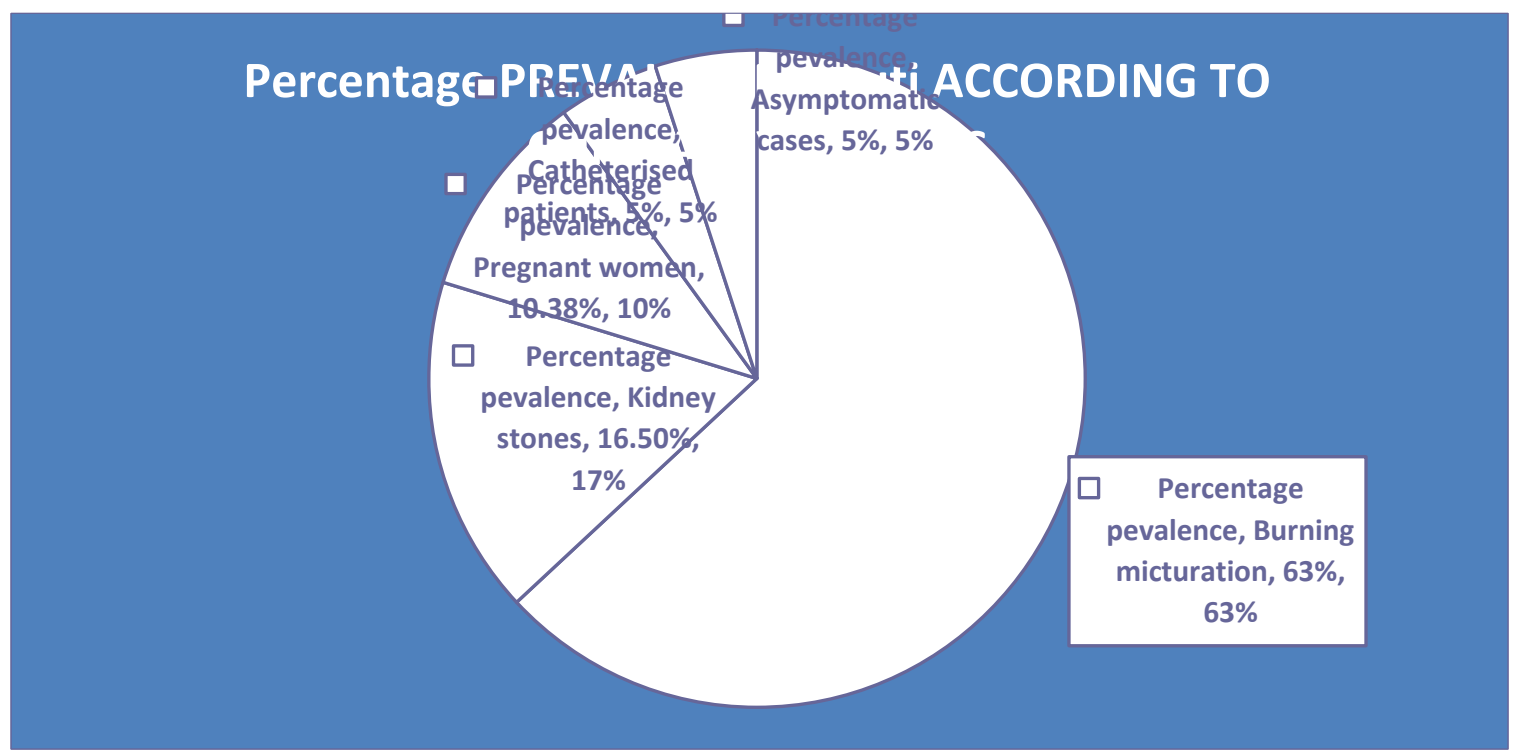

Table.1 Prevalence of Bacterial isolates from urine samples of patients (Total samples- 1078)

\begin{tabular}{|c|c|}
\hline Name of organism & Percentage \\
\hline Escherichia coli & $49.5 \%$ \\
\hline Klebsiella pneumoniae & $24.7 \%$ \\
\hline Pseudomonas aeruginosa & $9.5 \%$ \\
\hline Proteus mirabilis & $5.1 \%$ \\
\hline Citrobacter freundii & $2.5 \%$ \\
\hline Enterobacter & $1.9 \%$ \\
\hline Staphylococcus aureus & $2.1 \%$ \\
\hline Staphylococcus epidermidis & $1.3 \%$ \\
\hline Enterococcus spp. & $1.02 \%$ \\
\hline
\end{tabular}

The most commonly isolated bacteria being Escherichia coli (49.5\%) followed by Klebsiella pneumoniae (24.7\%). Some samples $(1.9 \%)$ showed mixed growth of two bacteria. The remaining isolates have been mentioned in Table 1 . The results of this study were in accordance to the studies of Joshi et al. (2011) from Bareilly, Chowdhury et al. (2015) from Bangladesh and Rameshprabu et al. (2014) from Pondicherry whose studies also showed maximum prevalence of Escherichia coli followed by Klebsiella pneumoniae. However, another study by Garg et al. (2015) from Aligarh showed highest prevalence of Escherichia coli followed by Citrobacter koseri. 
The bacteria isolated from the samples showed different susceptibility patterns (Table 2).They exhibited maximum sensitivity to Amikacin followed by Nitrofurantoin. Studies conducted by Mangaiarkkarasi et al. (2013) and Shalini et al. (2011) showed similar antibiotic pattern. Amikacin is known to have wide antibacterial spectrum among the different aminoglycosides and is resistant to aminoglycoside inactivating enzymes.
Nitrofurantoin is a urinary antiseptic. In their study Joshi et al. (2011) discussed very positive outcomes with Nitrofurantoin as it is cost effective and easily available in developing countries. Besides it can be used safely in pregnancy (Delzell et al., 2000) and causes narrow tissue distribution (James et al., 2002). In their study, Shaifali et al. (2012) from Lucknow also found the isolates exhibiting maximum susceptibility to Nitrofurantoin.

Table.2 Antibiotic Susceptibility pattern of the commonly occurring bacterial isolates from urine samples of patients

\begin{tabular}{|c|c|c|c|c|c|c|c|c|}
\hline Organism & $\begin{array}{l}\text { Amc } \\
(\%)\end{array}$ & $\begin{array}{l}\mathrm{Ak} \\
(\%)\end{array}$ & $\begin{array}{l}\mathrm{Caz} \\
(\%)\end{array}$ & $\begin{array}{l}\mathrm{Ci} \\
(\%)\end{array}$ & $\begin{array}{l}\text { Cot } \\
(\%)\end{array}$ & $\mathrm{G}(\%)$ & $\begin{array}{l}\mathrm{Ni} \\
(\%)\end{array}$ & $\begin{array}{l}\text { Nor } \\
(\%)\end{array}$ \\
\hline E. $\operatorname{coli}(\mathrm{S})$ & 11 & 94.5 & 67.1 & 46 & 24.8 & 61.4 & 89.8 & 80 \\
\hline (I) & 9.8 & 3.6 & 24.7 & 32.6 & 9.2 & 18 & 7.9 & 15.7 \\
\hline (R) & 79.2 & 1.9 & 8.2 & 21.4 & 76 & 20.5 & 2.3 & 4.3 \\
\hline K.pneumoniae(S) & 53.6 & 93 & 71.8 & 79 & 23.5 & 73.1 & 69.4 & 76.9 \\
\hline (I) & 15.4 & 5.3 & 16.3 & 19.1 & 3.6 & 2.9 & 12 & 9.1 \\
\hline (R) & 34 & 1.7 & 11.9 & 1.9 & 72.9 & 24 & 18.6 & 14 \\
\hline $\begin{array}{l}\text { Pseudoonas aeruginosa } \\
\text { (S) }\end{array}$ & -NA- & 79.3 & 83 & 57 & -NA- & 49.4 & -NA- & 75 \\
\hline (I) & -NA- & 18 & 14.7 & 27 & -NA- & 12 & -NA- & 11.3 \\
\hline (R) & -NA- & 2.7 & 1.02 & 16 & -NA- & 38.6 & -NA- & 13.7 \\
\hline Proteus mirabilis $(\mathrm{S})$ & 18.2 & 89.2 & 80.2 & 82.9 & 5 & 62.7 & 29.2 & -NA- \\
\hline (I) & 9.9 & 8.6 & 10.5 & 8 & 4.7 & 3.6 & 5.8 & -NA- \\
\hline (R) & 71.9 & 10.9 & 9.3 & 9.1 & 90.3 & 35.7 & 65 & -NA- \\
\hline S. aureus $(\mathrm{S})$ & 68.7 & -NA- & -NA- & 75.2 & 48.6 & 51.3 & 84.6 & 61 \\
\hline (I) & 13 & -NA- & -NA- & 15 & 6.7 & 7.9 & 9.5 & 3.3 \\
\hline (R) & 18.3 & -NA- & -NA- & 9.8 & 44.7 & 40.8 & 5.9 & 35.7 \\
\hline
\end{tabular}

(S)- Sensitive, (I)- Intermediate, (R)- Resistant, Amc - Amoxyclav, Ak- Amikacin, Caz- Ceftazidime, CiCiprofloxacin, Cot- Co-trimoxazole, G- Gentamicin, Ni- Nitrofurantoin, Nor- Norfloxacin

A higher incidence of resistance was observed for Co-trimoxazole and Amoxyclav in our study. Others (Yilmaz et al., 2005, Chowdhury et al., 2015) have also reported failure of effective treatment with Co-trimoxazole and Amoxyclav owing to increasing resistance. Manikandan et al. (2013) reported low susceptibility percentage against Amoxycillin in Klebsiella spp. Even studies from the United
States have shown resistance to Cotrimoxazole (Sahm et al., 2001). This increasing trend in the resistance pattern is due to indiscriminate or misuse of the antibiotics. Niranjan et al. (2014) reported multiple drug resistance in uropathogenic E.coli, which could be due to its widespread prevalence in the community. Lack of guidelines for appropriate use of Antimicrobial agents is another factor 
responsible for spread of resistance (Mahmoud et al., 2012).

Conclusively, factors like lack of health education in the rural population predispose them to various infections among which UTI is an important one. Besides, erratic use of antibiotics needs to be checked which is one of the major causes of spread of antimicrobial resistance and UTI being a community acquired infection the chances of spread of resistant bacterial strains makes it all the more dangerous.

\section{References}

Al-Jebouri, M.M. 1989. The Effect of Sublethal Concentrations of Disinfectants on Antibiotic-Resistant Staphylococcus aureus. J. Hospital Infec, 14(4):14-19.

Al-Jebouri1, M.M., Salih, A., Mdish. 2013. Antibiotic Resistance Pattern of Bacteria Isolated from Patients of Urinary Tract Infections in Iraq. Open J. Urol., (3): 124-131.

Bauer, A.W., Kirby, W.M.M., Sherris, J.C., Turck, M. $1966 . \quad$ Antibiotic susceptibility testing by a standardized single disk method. Amer. J. Clin. Pathol., (45): 493-496.

Bhargava, A.K., Kumar, A., Bohra, V.D., Jain, M., Singh, S.P. 2012. Chemical analysis of urinary stones in Bundelkhand region of Uttar Pradesh. J. Adv. Res. Biol. Sci., 4(3): 210-212.

Chowdhury, S., Parial, R. 2015. Antibiotic Susceptibility Patterns of Bacteria among Urinary Tract Infection Patients in Chittagong, Bangladesh. SMU Med. J., (2): 1 .

Cuttitta, F., Torres, D., Vogiatzis, D., Butta, C., Bellanca, M., Gueli, D. et al. 2014. Obesity and iron deficiency anemia as risk factors for asymptomatic bacteriuria. Eur. J. Int. Med., 25(3):
$292-5$

Delzell, J.E.Jr., Leferre, M.L. 2000. Urinary tract infections during pregnancy. Am. Fam. Physician, 61(3): 713-721.

Garg, N., Shukla, I., Rizvi, M., Ahmed, S.M., Khatoon, A., Khan, F. 2015. Microbiological Profile and Antibiotic Sensitivity Pattern of Bacterial Isolates Causing Urinary Tract Infection in Intensive Care Unit Patients in a Tertiary Care Hospital in Aligarh Region, India. Int. J. Curr. Microbiol. App. Sci., (1): 163-172.

Humayun, T., Iqbal, A. 2012. The Culture and Sensitivity Pattern of Urinary Tract Infections in Females of Reproductive Age Group. Ann. Pak. Inst. Med. Sci., 8(1): 19-22.

James, A.K., Laurie, J., Clyde, T., et al. 2002. Trends in Antimicrobial Resistance among Urinary Tract Infection Isolates of Escherichiacoli from Female Outpatients in the United States. Antimicrob. Agents Chemother., 46(8): 2540-2545.

Kahn, J. 2001. Evaluation of current activities of fluoroquinolones against gram-negative bacilli using centralized in vitro testing and electronic surveillance. Antimicrob. Agents Chemother., (45): 267-74.

Kebira, A.N., Ochola, P., Khamadi, S.A. 2009. Isolation and antimicrobial susceptibility testing of Escherichiacoli causing urinary tract infections. J. Appl. Biosci., (22): 13201325.

Kenechukwu, M., Chinekwu, O., Davidson, N., Golibe, U. 2006. Antibiotic sensitivity patterns in urinary tract infection at a Tertiary Hospital. $J$. Univ. Nigeria Med. Students. (3): 1631-1643.

Kumar, P., Das S. 2013. To study the Biochemical Analysis of Kidney Stone by Using FTIR Spectroscopy in the 
Patients with Renal Calculosis. Research and Reviews: J. Pharm. Analysis, 2(4): 27-32.

Mahmoud, Aly., Hanan, H., Balkhy. 2012. The prevalence of antimicrobial resistance in clinical isolates from Gulf Corporation Council countries. Antimicro. Resis. Infect. Con., (1): 26.

Mangaiarkkarasi, A., Meher Ali, R., Gopal. 2013. Study of Antimicrobial Susceptibility Pattern of Escherichia coli Isolated from clinical specimens in a Teaching Hospital, Pondicherry. RJPBCS, (4): 1365.

Manikandan C., Amsath A. 2013. Antibiotic susceptibility pattern of Klebsiella pneumoniae isolated from urine samples. Int. J. Curr. Microbiol. App. Sci., 2(8): 330-337.

Niranjan, V., Malini, A. 2013. Antimicrobial resistance pattern in Escherichia coli causing urinary tract infection among inpatients. Ind. J. Med. Res., 139: 945948.

Omoregie, R., Eghafonia, N.O. 2009. Urinary tract infection among asymptomatic HIV patients in Benin City, Nigeria. Bristish J. Biomed. Sci., 66(4).

Rajagopalan, S. 2000. Urinary tract infections.in: Beer MH, Jones TV, eds Merck manual of geriatrics, $3^{\text {rd }}$ eds, section 12 ch. 100 .

Rameshprabu., Rameshkannan., Priyanka. 2014. Antibiotic sensitivity and resistance patterns in community acquired urinary tract infections in a tertiary care hospital in Pondicherry. Ind. J. Basic and App. Med. Res., (4): 139-143.

Sahm, D.F., Critchley, I.A., Kelly, L.J., Karlowsky, J.A., Mayfield, D.C., Thornsberry. C., Mauriz, Y.R.,

Schneeberger, C., Kazemier, B.M., Geerlings, S.E. 2014. Asymptomatic bacteriuria and urinary tract infections in special patient groups: women with diabetes mellitus and pregnant women. Curr. Opin. Infect. Dis., 27(1): 108 14.

Shaifali, I., Gupta, U., Mahmood, S.E., Ahmad, J. 2012. Antibiotic susceptibility patterns of urinary pathogens in female outpatients. North. Am. J. Med. Sci., 163-9.

Shalini, Joshi, M.C., Rashid, M.K., Joshi, H.S. 2011. Study of Antibiotic Sensitivity Pattern in Urinary Tract Infection at a Tertiary Hospital. NJIRM., 2(3).

Turck, M., Goffe, B.S., Petersdorf, R.G. 1962. Bacteriuria of pregnancy Relation to Socioeconomic factors. $N$. Eng. J. Med., (266): 857-860.

Yilmaz, K., Nilay, C., Aysegül, G., et al. 2005. Co-trimoxazole and quinolone resistance in Escherichia coli isolated from urinary tract infections over the last 10 years. Int. J. Antimicrobial Agents, 26(1): 75-77.

\section{How to cite this article:}

Lekha Tuli, Sujeet Rai, Dilshad Arif, Deepak K. Singh. 2016. Bacteriological profile and Antimicrobial Susceptibility pattern of isolates from Urinary Tract Infections in Eastern Uttar Pradesh, India. Int.J.Curr.Microbiol.App.Sci. 5(3): 428-435. doi: http://dx.doi.org/10.20546/ijcmas.2016.503.049 